\title{
Variability of the Norwegian Atlantic Current and associated eddy field from surface drifters
}

\author{
M. Andersson, ${ }^{1}$ K. A. Orvik, ${ }^{1}$ J. H. LaCasce, ${ }^{2}$ I. Koszalka, ${ }^{2}$ and C. Mauritzen ${ }^{3}$ \\ Received 28 February 2011; revised 18 May 2011; accepted 31 May 2011; published 26 August 2011.
}

[1] The Norwegian Atlantic Current (NwAC) and its eddy field are examined using data from surface drifters. The data set used spans nearly 20 years, from June 1991 to December 2009. The results are largely consistent with previous estimates, which were based on data from the first decade only. With our new data set, statistical analysis of the mean fields can be calculated with larger confidence. The two branches of the NwAC, one over the continental slope and a second further offshore, are clearly captured. The Norwegian Coastal Current is also resolved. In addition, we observe a semipermanent anticylonic eddy in the Lofoten Basin, a feature seen previously in hydrography and in models. The eddy kinetic energy (EKE) is intensified along the path of the NwAC, with the largest values occurring in the Lofoten Basin. The strongest currents, exceeding $100 \mathrm{~cm} \mathrm{~s}^{-1}$, occur west of Lofoten. Lateral diffusivities were computed in five domains and ranged from $1-5 \times 10^{7} \mathrm{~cm}^{2} \mathrm{~s}^{-1}$. The Lagrangian integral time and space scales are 1-2 days and 7-23 km, respectively. The data set allows studies of seasonal and interannual variations as well. The strongest seasonal signal is in the NwAC itself, as the mean flow strengthens by approximately $20 \%$ in winter. The EKE and diffusivities on the other hand do not exhibit consistent seasonality in the sampled regions. There are no consistent indications of changes in either the mean or fluctuating surface velocities between the 1990s and 2000s.

Citation: Andersson, M., K. A. Orvik, J. H. LaCasce, I. Koszalka, and C. Mauritzen (2011), Variability of the Norwegian Atlantic Current and associated eddy field from surface drifters, J. Geophys. Res., 116, C08032, doi:10.1029/2011JC007078.

\section{Introduction}

[2] During the International Polar Year (IPY) a dedicated surface drifter project, the POLEWARD experiment, was conducted in the Nordic Seas during the period 2007-2009. In the experiment, 148 surface drifters, drogued at $15 \mathrm{~m}$, were released at various locations west of the Norwegian coast, in the Barents Sea and south of Spitsbergen. The primary goal was to study the evolution of the warm waters entering the Nordic Seas as they flow north toward Spitsbergen, cool and become denser. The main feature of this flow is the Norwegian Atlantic Current (NwAC), the northern extension of the North Atlantic Current (NAC). This is the shallow branch of the thermohaline circulation, and the cooling and freshening which occurs in the Nordic Seas is fundamental in determining the density of the North Atlantic Deep Water which returns to the North Atlantic [Mauritzen, 1996].

[3] The NwAC commences at the Iceland-Scotland ridge, continuing northward in two branches [Dietrich et al., 1980; Orvik and Niiler, 2002]. It is strongly steered by topography

\footnotetext{
${ }^{1}$ Geophysical Institute, University of Bergen, Bergen, Norway.

${ }^{2}$ Institute of Geosciences, University of Oslo, Oslo, Norway.

${ }^{3}$ Norwegian Meteorological Institute, Oslo, Norway.

Copyright 2011 by the American Geophysical Union. 0148-0227/11/2011JC007078
}

and its path can accordingly be traced along the isobaths [Poulain et al., 1996; Orvik and Niiler, 2002]. The eastern branch of the NwAC lies over the continental slope and has a significant barotropic component. A portion of this branch flows into the Barents Sea and the Arctic Ocean, linking the North Atlantic, Arctic Ocean and the Barents Sea [Orvik and Skagseth, 2005]. The western branch is a baroclinic jet along the Polar front; it can be traced throughout the Nordic Seas toward the Fram Strait [Orvik et al., 2001; Orvik and Niiler, 2002].

[4] There is significant exchange between the two branches, as has been observed both with surface drifters [Poulain et al., 1996; Orvik and Niiler, 2002; Jakobsen et al., 2003] and with subsurface floats [Søiland et al., 2008].

[5] Using position and velocity data from surface drifters, Poulain et al. [1996] computed quasi-Eulerian statistics using drifter data from the 1990s. The authors found a vigorous eddy field near the principal currents and in the Lofoten Basin. The latter has a distinct hydrographic signature as well, as the isopycnals of the warm Atlantic water lay deeper in that basin than further north and south [Orvik, 2004]. The Lofoten Basin evidently acts as a reservoir for Atlantic water, facilitating heat exchange with the atmosphere. There are indications that warm water is transported into the basin from the eastern branch of the NwAC via eddies [e.g., Rossby et al., 2009]. The eddies also affect the circulation in the basin. In particular, model simulations suggest that 
DEPTH



Figure 1. Major pathways of Atlantic water with bathymetry of the Nordic Seas and sites of drifter deployments by the POLEWARD project (red stars), historical deployments (green stars), and recent non-POLEWARD deployments (black stars).

anticyclonic eddies migrate into the interior where they sustain a quasi-permanent anticyclonic circulation $K o ̈ h l$ [2007].

[6] Subsequent drifter studies in the Nordic Seas have provided greater detail of the flows [Orvik and Niiler, 2002; Jakobsen et al., 2003]. Recently, Koszalka et al. [2011] compared two methods of estimating mean velocities and diffusivities from surface drifter observations from the Nordic Seas. It was concluded that the clustering method, relying on a clustering algorithm, provides finer resolution in densely sampled regions compared to the more conventional binning method. The binning technique, on the other hand, is suitable for temporal variability analysis. In the present study, the POLEWARD data is used in combination with the existing data to obtain new estimates. As the combined data set is larger, the statistical estimates are more robust than previously. And as they span a longer period of time, they permit a study of the seasonal variability and of the contrast between the 1990 s with the 2000 s. For the first time, temporal variability analysis of diffusivities in the Nordic Seas using drifter data are performed.

[7] Previously, Orvik and Skagseth [2003] suggested that the variability in the Nordic Seas is correlated with the wind stress curl over the North Atlantic. If so, the variability might also be correlated with the NAO index. The early 1990s correspond to strong positive NAO years, while the 2000s had more fluctuating values of NAO [Hurrell, 1995], and this would imply a difference in variability between the 2 decades.

[8] The paper is organized as follows. In section 2 , the drifters, the deployments and the methods of data processing are discussed. In section 3, the Eulerian mean circulation, Lagrangian statistics, and seasonal and interannual vari- ability are presented. Section 4 concludes with a discussion of the results.

\section{Data and Methods}

[9] The 148 POLEWARD surface drifters that were deployed in the Nordic Seas in the period from June 2007 to July 2009 yield 15,200 buoy days. The drifters were deployed under the Surface Velocity Program (SVP) of the Global Drifter Program. The historical data is from SVP drifters in the same region. The combined set comprises more than 77,000 buoy days of position from 487 drifters, from June 1991 to December 2009.

[10] The drifter consists of a surface buoy, with a transmitter and a temperature sensor, and a subsurface drogue centered at $15 \mathrm{~m}$ depth. The drifter has a tether strain sensor to verify the presence of the drogue. Only data from drogued drifters was used in this study. The drifters follow the nearsurface flow in the mixed layer, including the Ekman drift [Niiler et al., 1987; Lumpkin et al., 2001]. They are tracked by the Argos satellite system, yielding positions with 150 $1000 \mathrm{~m}$ accuracy, with 16-20 satellite fixes per day. The AOML's (Atlantic Oceanographic and Meteorological Laboratory) drifter Data Assembly Center (DAC) assembles the raw data, applies quality control, and interpolates them to uniform 6 hourly intervals using a kriging technique [Lumpkin and Pazos, 2006]. This initial processing of the data, including quality control and interpolation of the positions to $6 \mathrm{~h}$ interval, is described in detail by Hansen and Poulain [1996].

[11] The drifters were released at 5 deployment sites along the path of the NwAC: the Svinøy Section, west of Lofoten Islands, Bjørnøya, the Barents Sea opening and in the Lofoten Basin. They were deployed during the June/July 2007 period, in October 2007, March 2008, October 2008, and in June/July 2009. The deployment positions, along with the major pathways of Atlantic water, are shown in Figure 1.

[12] The area of investigation stretches from $30^{\circ} \mathrm{W}$ to $30^{\circ} \mathrm{E}$ and $60^{\circ} \mathrm{N}$ to $80^{\circ} \mathrm{N}$. It encompasses the Greenland, Lofoten, and Norwegian basins; the Iceland Plateau; the Barents Sea opening and the region where the Atlantic water enters the Nordic Seas. For the subsequent statistics, the area is limited to $15^{\circ} \mathrm{W}$ to $19^{\circ} \mathrm{E}$ and $60^{\circ} \mathrm{N}$ to $74^{\circ} \mathrm{N}$, as this is the region with the greatest data availability. The different areas and the drifter trajectories are shown in Figure 2.

[13] Drifter velocities were obtained by differencing their positions. To remove the high frequency current components, especially the tidal and inertial currents, the interpolated positions were low-pass filtered with a Butterworth filter with a cut-off period of $25 \mathrm{~h}$. Other than this filtering the data were not averaged in time. Drifters with time gaps greater than 1 day were treated as separated drifters.

[14] Drifters are not fully Lagrangian, as they only track horizontal velocities. Nevertheless, they can be used to infer transport properties of the surface flow [Davis, 1991]. Specifically, the evolution of a passive tracer can be described by the mean initial field from the statistics of single particles [Davis, 1983]. This involves both the mean velocity and the diffusivity, both of which are assumed to vary in space. The diffusivity parametrization assumes that the dispersion is due to small-scale eddies, i.e., that there is a scale separation between eddies and the mean flow. 
POLEWARD (RED) + NON POLEWARD (BLUE) TRAJECTORIES

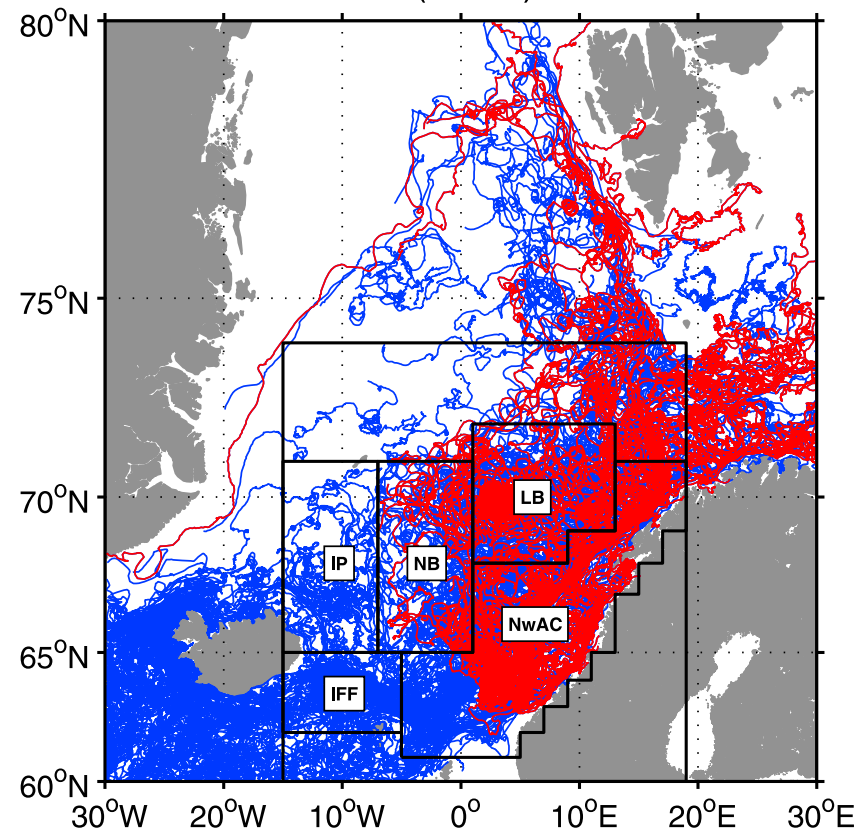

Figure 2. Drogued drifter trajectories from GDP (Global Drifter Program) database; POLEWARD trajectories in red and non-POLEWARD data in blue. The five domains where the Lagrangian statistics have been estimated are shown. IFF, Iceland-Faroe Front; IP, Iceland Plateau; NB, Norwegian Basin; LB, Lofoten Basin; NwAC, Norwegian Atlantic Current.

[15] To obtain pseudo-Eulerian averages, we grouped the drifter velocities into geographical bins and calculated means and variances [e.g., Poulain and Niiler, 1989; Poulain et al., 1996; Swenson and Niiler, 1996; Fratantoni, 2001]. The robustness of such maps is discussed by Lumpkin [2003]. The internal Rossby radius in the Nordic Seas is $\sim 10 \mathrm{~km}$ [Chelton et al., 1998] and the dominant eddy scale is about $50 \mathrm{~km}$ [Poulain et al., 1996]. As such, we grouped the observations into $2^{\circ}$ longitude $\times 1^{\circ}$ latitude bins, or roughly $110 \mathrm{~km}$ square, which provides a reasonable depiction of the major circulation features. To ensure that the bins contain sufficient data to form statistically reliable values only bins containing more than 50 observations and from at least 2 different drifters were used [Poulain et al., 1996; Poulain and Niiler, 1989]. Smaller bins does not provide enough data in bins to study seasonal and decadal variability.

[16] In each bin, $\mathbf{U}(x, y)$ is computed as the ensemble average of all available velocity measurements $\mathbf{u}(x, y, t)$, where $x$ and $y$ denote the position and $t$ the time. The residual velocity, $\mathbf{u}^{\prime}(x, y, t)$, is defined as the deviation of $\mathbf{u}(x, y, t)$ from $\mathbf{U}(x, y)$. The eddy kinetic energy (EKE) is $1 / 2\left(\left\langle u^{\prime 2}\right\rangle+\left\langle v^{\prime 2}\right\rangle\right)$, where $u$ and $v$ are the zonal and meridional velocities, respectively, and where the brackets \langle\rangle denote an average over the particle ensemble. All observations were accorded equal weight, as described by Davis [1991].

[17] Principal component analysis on the velocity fields was performed to determine the principal axes of current velocity variance (kinetic energy) [Emery and Thomson,
2001]. The trend and mean were removed from the data in each bin.

[18] In calculating the Lagrangian averages, we assume the velocity statistics are stationary. The diffusivity is calculated following Taylor [1921], as prescribed by Davis [1991]

$$
\kappa(t) \equiv \frac{1}{2} \frac{d}{d t}\left\langle X^{2}\right\rangle=\langle X(t) u(t)\rangle=\int_{0}^{t}\langle u(X, t) u(X, \tau)\rangle d \tau,
$$

where $X(t)$ is the displacement and $\tau$ is the time lag. The diffusivity thus is the integral of the velocity autocorrelation and is calculated from the residual velocities. If the flow is stationary, then

$$
\kappa(t)=u^{\prime 2} \int_{0}^{t} R(\tau) d \tau
$$

where $u^{\prime 2}$ is the velocity variance and $R(\tau)$ the time-lagged velocity autocorrelation, [Lumpkin et al., 2001; LaCasce, 2008]. This equation holds in locally homogeneous regions. The integral of the autocorrelation, normalized by the variance of the residual velocities, is the Lagrangian time scale. (For definitions of the Lagrangian time and length scales see Equations A1 and A2 in Appendix A.) Following Taylor [1921], the diffusivity obtains in the limit $t \rightarrow \infty$. But as the record lengths are finite and noise dominates the autocorrelation function at large lags [Lumpkin et al., 2001], the integral is necessarily truncated at a finite lag. The most common approach is to integrate to the first zero crossing of $R$ [e.g. Freeland et al., 1975; Krauss and Böning, 1987; Poulain and Niiler, 1989]. Integrating to the first zero crossing of $R$ corresponds to the first maximum of the integral time scale and the resulting value is usually an upper bound to the actual value. However others integrate to a constant, prechosen lag (e.g., 20 days) [Speer et al., 1999]. In this case, the lag is chosen by visual inspection of the integral curves.

[19] We adopt an approach similar to the latter above. Specifically, we estimate the diffusivities, and the corresponding time and length scales, by averaging the autocorrelation integral over the period from 6 to 10 days. In many cases, the integral levels off after several days, and using this period provides a reasonable average. Using a shorter time is problematic as the integral has not yet converged [e.g., Koszalka and LaCasce, 2010] and longer times are not desirable as the errors increase as the square root of time [Davis, 1991]. An example of the mean autocorrelation and its integral, from the Lofoten Basin region, is shown in Figure 3.

[20] We calculated diffusivities and integral scales in five geographical domains. These are the Iceland-Faroe Front (IFF) region, the Iceland Plateau (IP), the Norwegian (NB) and Lofoten basins (LB), and the NwAC region (Figure 2). Using larger regions for the diffusivities improves their convergence, as the diffusivity is a more Lagrangian statistic, involving averages over particle paths.

[21] Throughout the paper, errors were estimated using the independent number of observations, $n^{*}$. The value of $n^{*}$ was computed as $n \Delta t / 2 T_{L}$, where $n$ is the total number of observations, $\Delta t$ is the sampling interval and $T_{L}$ the Lagrangian timescale, here assumed to be 1 day. 

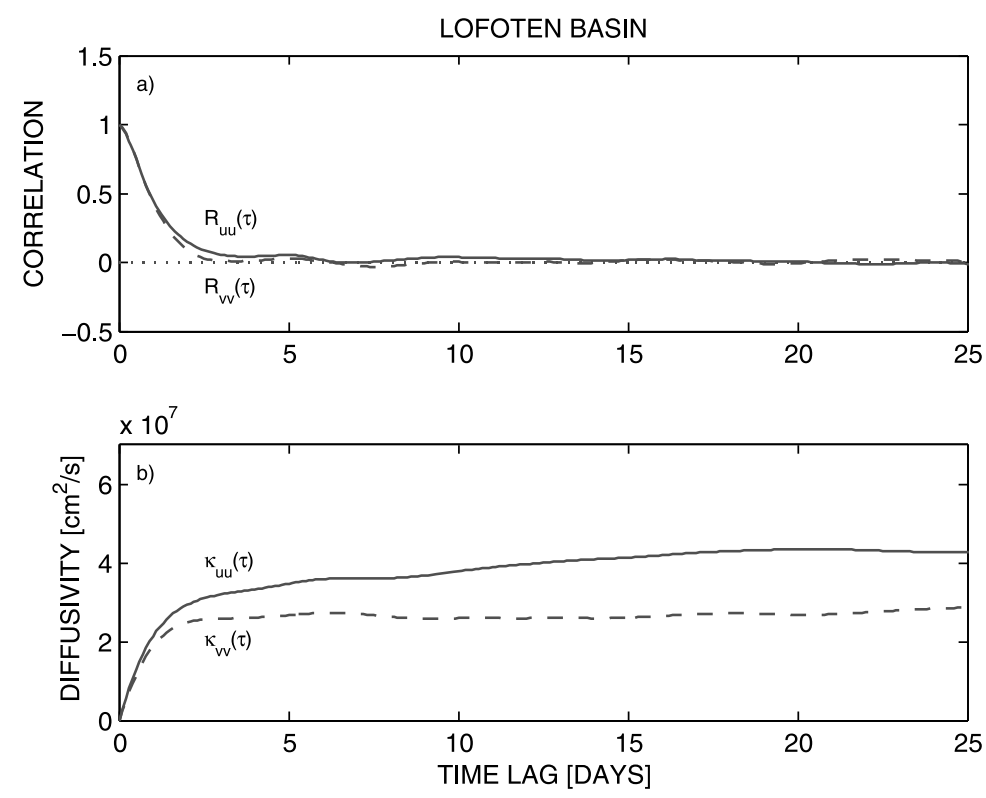

Figure 3. Time-lagged (a) velocity variance and (b) diffusivity versus time lag for the Lofoten Basin domain.

[22] To study how the statistics vary with season, we require that the observations are available for most of the year. The distribution of observations by month is close to uniform, as shown in Figure 4. We divide the data into two subsets, one representing summer (May to October) and the other winter (November to April). The data from the summer season constitutes $53 \%$ of the whole set and that from the winter season the remaining $47 \%$.

[23] There are nevertheless regional variations in the coverage, as expected due to spatially varying mean currents and eddy field and intermittent deployments; there are more observations in some regions in winter than in summer, and vice versa. To quantify this, we used the method of Lumpkin [2003], in which each observation is assigned a complex number, with unit amplitude and a phase determined by year day. The numbers are then averaged in the $2^{\circ} \times 1^{\circ}$ bins. The results are shown in Figure 5. An amplitude of zero indicates homogeneous sampling through the seasons and an amplitude of one implies one season is sampled exclusively. The sampling is reasonably uniform, except in a few loca-
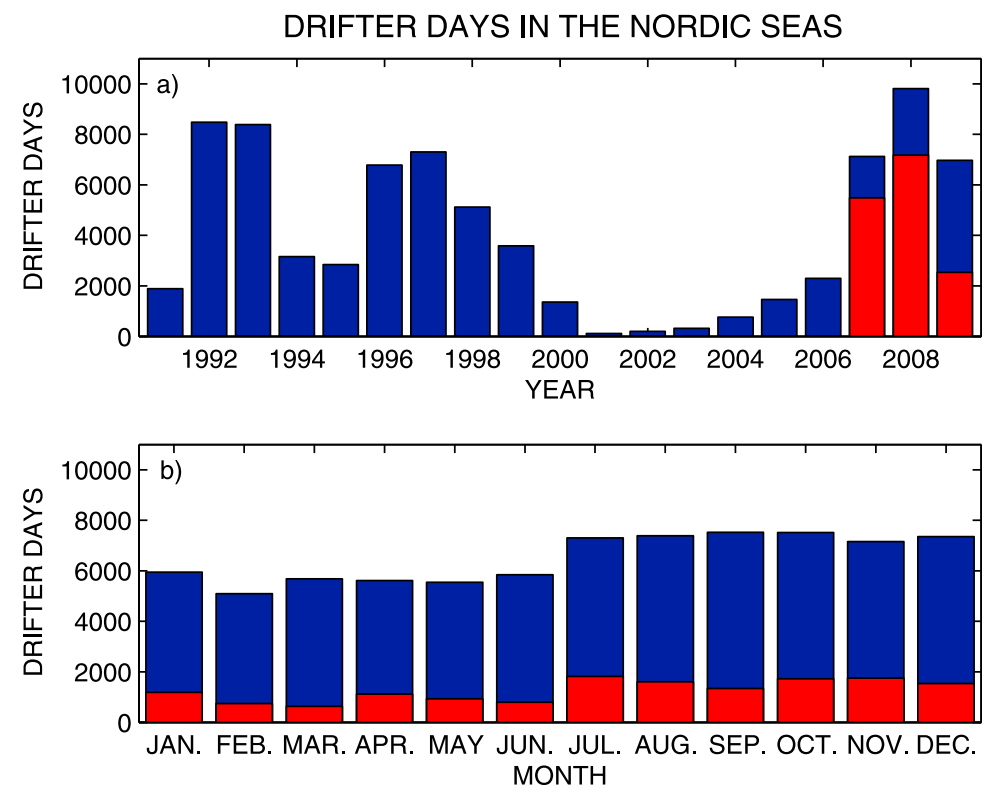

Figure 4. Number of drifter days (a) per year and (b) per month. POLEWARD observations are marked in red. 

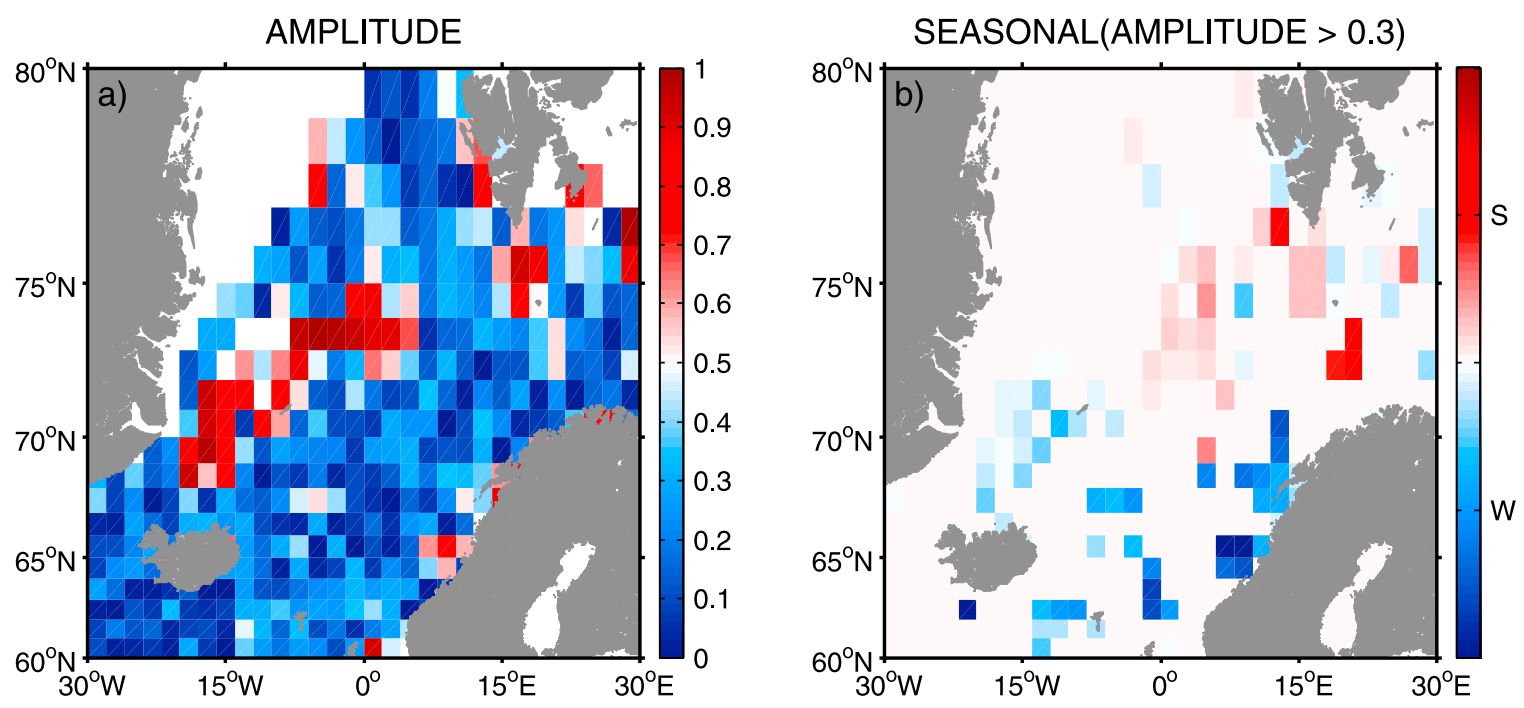

Figure 5. (a) Amplitude of the seasonal observational bias and (b) the ratio of summer to winter observations for bins where the amplitude exceeds 0.3 . Blue areas show where winter data is over represented and red areas show where summer data is over represented, the more intense the color the greater the difference.

tions. It is large at the western periphery, where the sampling is sparse. But it is also elevated in some regions in the east (Figure 5a).

[24] In Figure 5b, the ratio of summer to winter observations is plotted for regions where the amplitude exceeds 0.3 . There are several regions along the Norwegian coast which have an excess of wintertime observations. Parts of the western Barents Sea on the other hand and the Lofoten Basin were sampled more in the summertime, due to summertime deployments.

[25] As we have data spanning almost 20 years, we can also examine the change in statistics between the first and second decades. Specifically we will compare the mean velocities, the eddy kinetic energies and diffusivities for the two periods. Defining the first period to be from 1991 to 1998 and the second from 1999 to 2009 resulted in a nearly even distribution of observations. The first period corresponds to $56 \%$ of the whole set and the second the remaining 44\%. Nevertheless, the regional sampling varies in the two periods, and this will be seen to be important. To reduce seasonal biasing, only bins with more than 25 observations from summer and 25 observations from winter were included.

\section{Results}

\subsection{Eulerian Mean Circulation 1991-2009}

[26] The mean velocities for the entire sampled period are shown in Figure 6. Qualitatively the current structure is consistent with earlier studies: Both the eastern and the western branch of the NwAC are clearly seen, with strongest currents just west of the Lofoten and Vesterålen Islands. The strongest currents exceed $100 \mathrm{~cm} \mathrm{~s}^{-1}$, north of the Lofoten Basin and near the Lofoten Islands. The eastern branch follows the Norwegian shelf edge and its continuation towards the Fram Strait. There is clear exchange between the eastern branch and the Norwegian Coastal Current (NwCC), which lies near the coast. There is also a bifur- cation north of Norway, with part of the flow entering the Barents Sea. The western branch follows the topographic slope of the Vøring Plateau toward Jan Mayen. Then it turns northeast, following Mohn's Ridge. West of Bjørnøya, it turns northward and continues along the Knipovich Ridge toward the Fram Strait. An anticyclonic recirculation, though barely resolved, is seen too in the western Lofoten Basin.

[27] The eddy kinetic energy and principal axes of the variance are shown in Figures 7 and 8. The largest kinetic energies occur where the mean currents are strongest. There

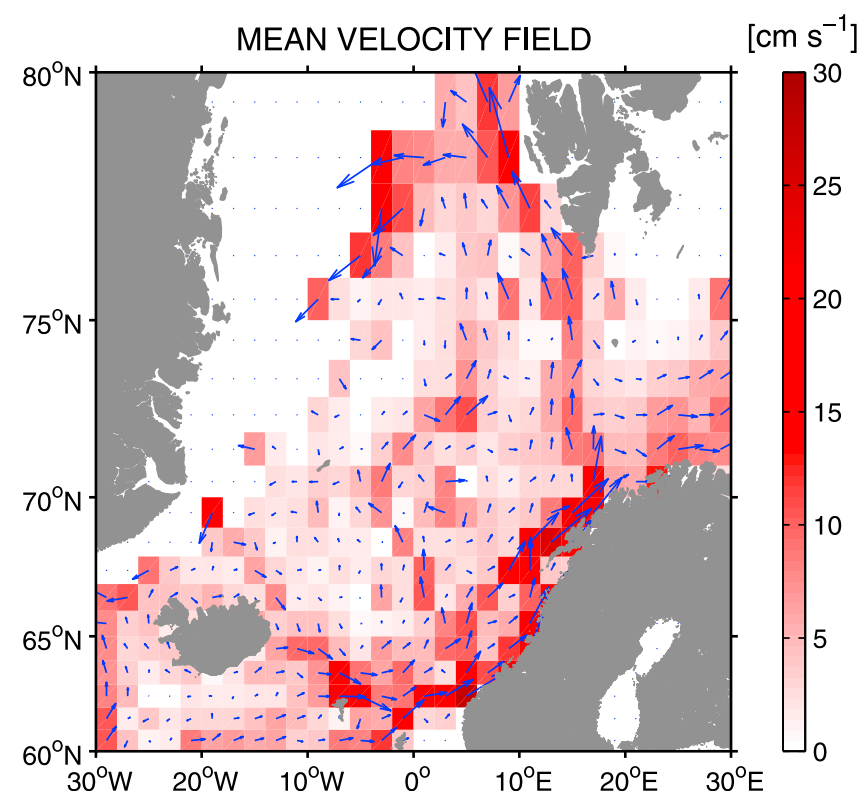

Figure 6. Mean velocity vectors computed from drogued observations in $2^{\circ}$ longitude by $1^{\circ}$ latitude bins. The results for bins with less than 50 six hourly observations and from less than two different drifters are not shown. 


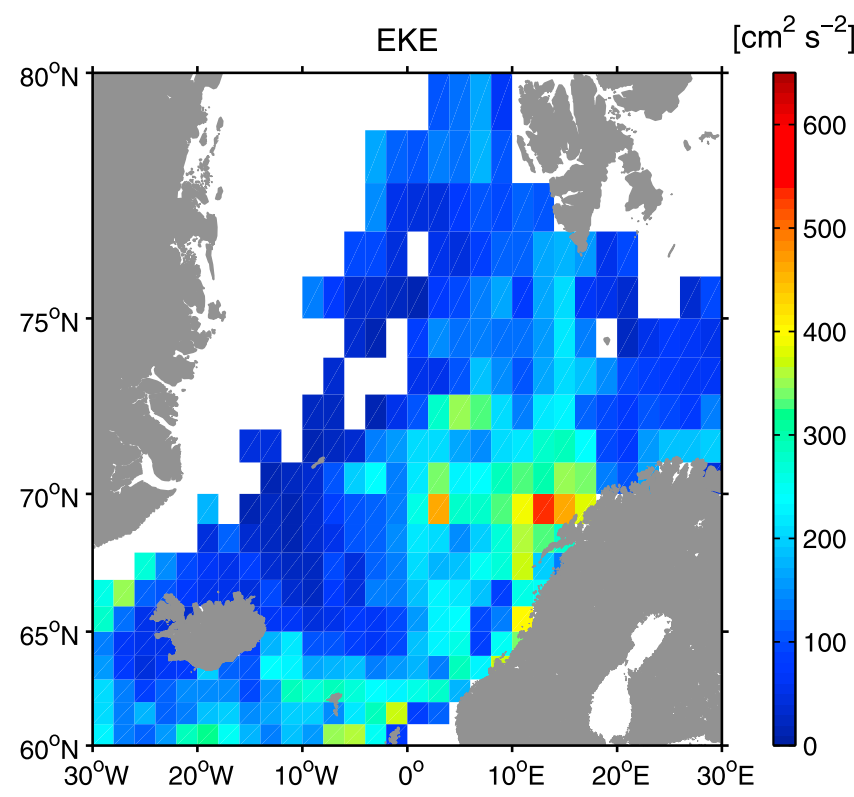

Figure 7. Distribution of the fluctuation or eddy kinetic energy calculated from drifter data in $2^{\circ}$ longitude by $1^{\circ}$ latitude bins.

are both energetic regions (near the Iceland Faroe Front, the NwAC and in the Lofoten Basin) and quiescent regions (the Iceland Plateau and the Norwegian Basin). The largest eddy kinetic energies $\left(>530 \mathrm{~cm}^{2} \mathrm{~s}^{-2}\right)$ are found in the Lofoten Basin, northwest of the Lofoten and Vesterålen Islands. The minimum energies $\left(<20 \mathrm{~cm}^{2} \mathrm{~s}^{-2}\right)$ occur near the Iceland plateau. The axes suggest the variability is most anisotropic where the mean currents are strongest. Here the variability is also aligned with the topography. Offshore, the variability is more nearly isotropic. It has been suggested that there are jet-like structures extending westward from the strong currents [Poulain et al., 1996; Köhl, 2007; Rossby et al., 2009], but such structures are not apparent in the variance axes.

[28] Our variance contours are similar to those of Poulain et al. [1996, Figure 3], except that their values are slightly greater in the Lofoten region than ours. This may result from the fact that we only use drogued drifter data while Poulain et al. [1996] also include wind-corrected data, or simply that we have more data, with targeted deployments in the Lofoten Basin.

\subsection{Diffusivities 1991-2009}

[29] We calculated diffusivities in five larger regions, denoted the Iceland Faroe front (IFF), the Iceland Plateau (IP), the Norwegian (NB) and Lofoten (LB) basins, and the NwAC region (Figure 2). The results are shown in Figure 9. Figure 9a shows the velocity variances in each of the regions, and Figure $9 \mathrm{~b}$ shows the diffusivities, calculated using Equation 2. The corresponding values obtained by Poulain et al. [1996] are marked in green. The variances and diffusivities are also listed in Table A1 in Appendix A, along with the corresponding integral time and space scales.

[30] Regarding the variances, we see that the zonal and meridional estimates are the same within the errors in all five regions. As could be anticipated from the previous results, the weakest variability is in the Iceland Plateau region (with variances of $<40 \mathrm{~cm}^{2} \mathrm{~s}^{-2}$ ). The variances are over 6 times greater in the Lofoten Basin (near $260 \mathrm{~cm}^{2} \mathrm{~s}^{-2}$ ). The estimates in all five regions are consistent with those of Poulain et al. [1996].

[31] The diffusivities show similar variations, with the smallest values in the Iceland Plateau region and the largest in the Lofoten Basin. The diffusivities are near $1 \times 10^{7} \mathrm{~cm}^{2} \mathrm{~s}^{-1}$ in the former and 2.7-3.6 $\times 10^{7} \mathrm{~cm}^{2} \mathrm{~s}^{-1}$ in the latter. In this case there are significant differences between our values and the values obtained by Poulain et al. [1996]. Theirs are generally larger than ours, particularly in the NwAC region. The result is in line with Koszalka et al. [2011] who found that the diffusivities were suppressed at the core of the NwAC, while they were elevated in the Lofoten Basin.

[32] As discussed in section 2, the diffusivity is proportional to the variance for a stationary flow. As our variances are comparable to those of Poulain et al. [1996], the differences in diffusivity evidently stem from the Lagrangian time scales. Poulain et al. [1996] used the maximum values of the diffusivities in the 0-20 day range whereas we used the mean value between 6 and 10 days. To check this, we recalculated the diffusivities using data from the same period (1991-1995) and used the maximum value during the 0-20 day period. This yielded values comparable to those of Poulain et al. [1996], except in the NwAC region, where our diffusivities were still somewhat lower. We also calculate the residual velocities in a different manner than Poulain et al. [1996], but as our variances are comparable, this evidently does not affect the diffusivities. (We calculate the means in geographical bins and interpolate them onto individual trajectories to obtain the residuals. Poulain et al. [1996] calculated Lagrangian averages along the trajectories and subtracted those.)

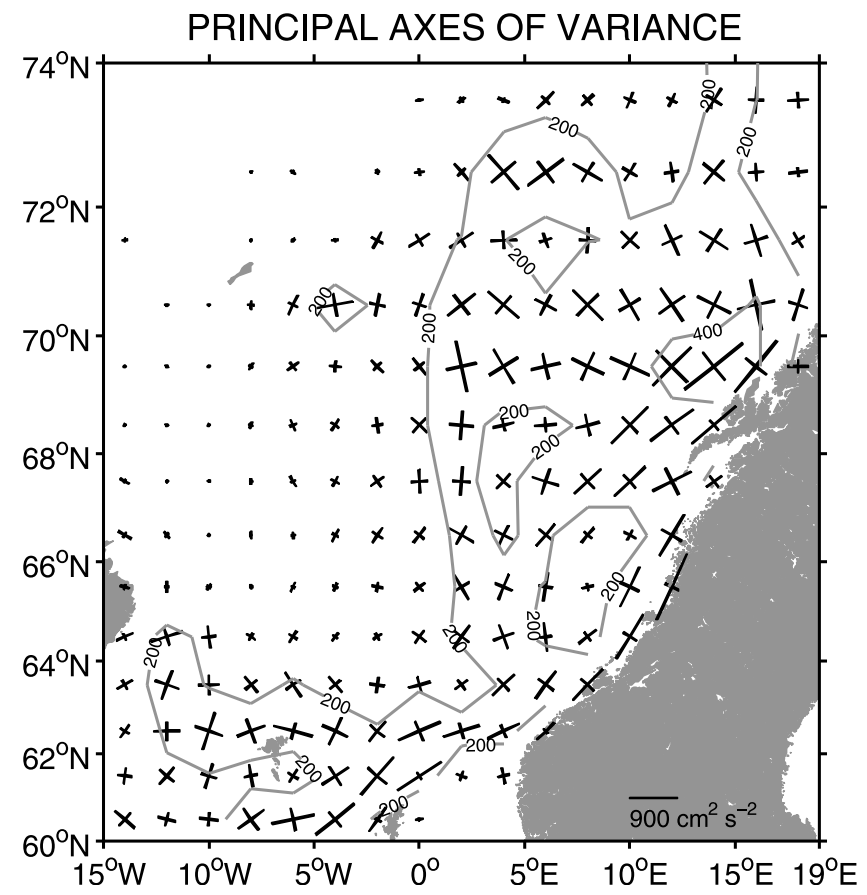

Figure 8. Principal axes of variance and contours of eddy kinetic energy computed from drogued observation data in $2^{\circ}$ longitude by $1^{\circ}$ latitude bins. 

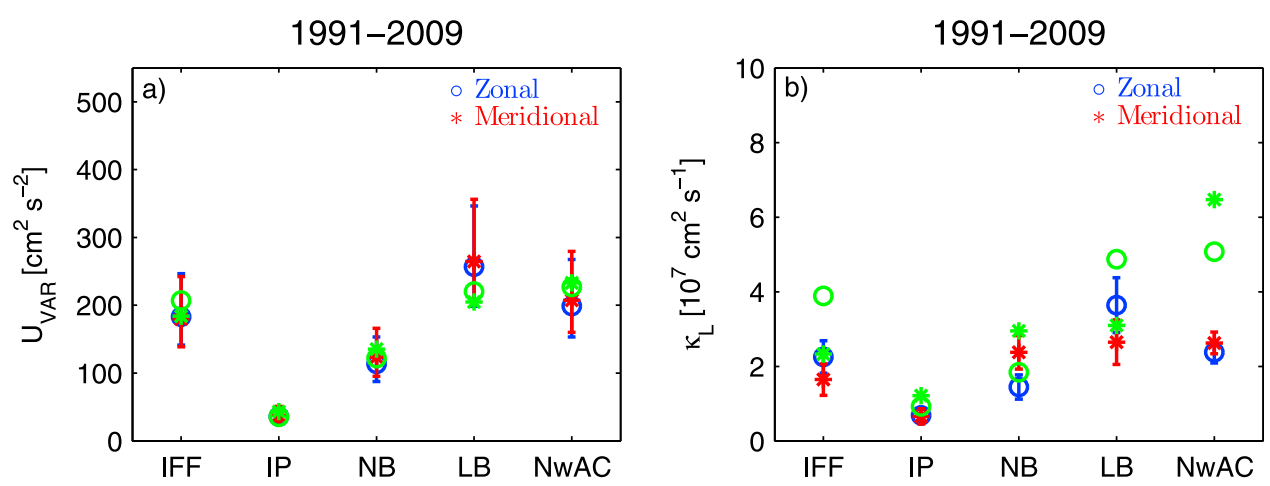

Figure 9. (a) Velocity variance and (b) diffusivity as computed in the five domains in the Nordic Seas. The open circles and stars denote zonal and meridional directions, respectively. The error bars show the $95 \%$ confidence level based on a chi-square probability distribution with $n^{*}-1$ degrees of freedom for the variances and a Student's $t$ distribution for the diffusivities. The green marks are the results from Poulain et al. [1996].

[33] The Lagrangian integral timescales vary from 11.5 days in most regions. The length scales are mostly between 10 and $20 \mathrm{~km}$, with the smallest values occurring in the Iceland Plateau region. All values are listed in Table A1 in Appendix A.

\subsection{Seasonal and Decadal Variability}

[34] To examine seasonal variations, we divided the data into two sets, one for summer (May to October) and the other for winter (November to April). Then we calculated velocity statistics for each period and compared them. As noted, each season has approximately the same amount of data, and the regional coverage is also similar during the two periods.

[35] The mean circulations for the two seasons are shown in Figure 10. The overall picture is very similar, indicating that there are no major changes in the structure of the currents. Both the eastern and the western branches of the $\mathrm{NwAC}$ are present, as is the NwCC. In the difference between the means, shown in Figure 11, the gray shaded bins represent means which differ at the $95 \%$ level, as determined by a vectorial $t$ test [Garraffo et al., 2001]. (Using the $t$ test assumes the data are normally distributed. We tested this by calculating the kurtosis of the residual velocities in each bin, and found that the values were indeed generally near three. A timescale of 2 days was used to determine the degrees of freedom in each bin.) While the means are different in a number of bins, the bins with significant differences are spread approximately uniformly throughout the domain. There is nevertheless evidence for winter intensification in several locations: near the inflow $\left(0^{\circ}\right.$ and $\left.63^{\circ} \mathrm{N}\right)$, at Svinøy, west of Lofoten Islands and in the continuation towards Spitsbergen. Furthermore, the anticyclonic recirculation in the Lofoten Basin is seen in summer but not in winter.

[36] Some of these differences stem from differences in sampling. Particularly in the Lofoten Basin, where there was a targeted deployment during a summer cruise in 2009. A number of these drifters were launched in or near the eddy.
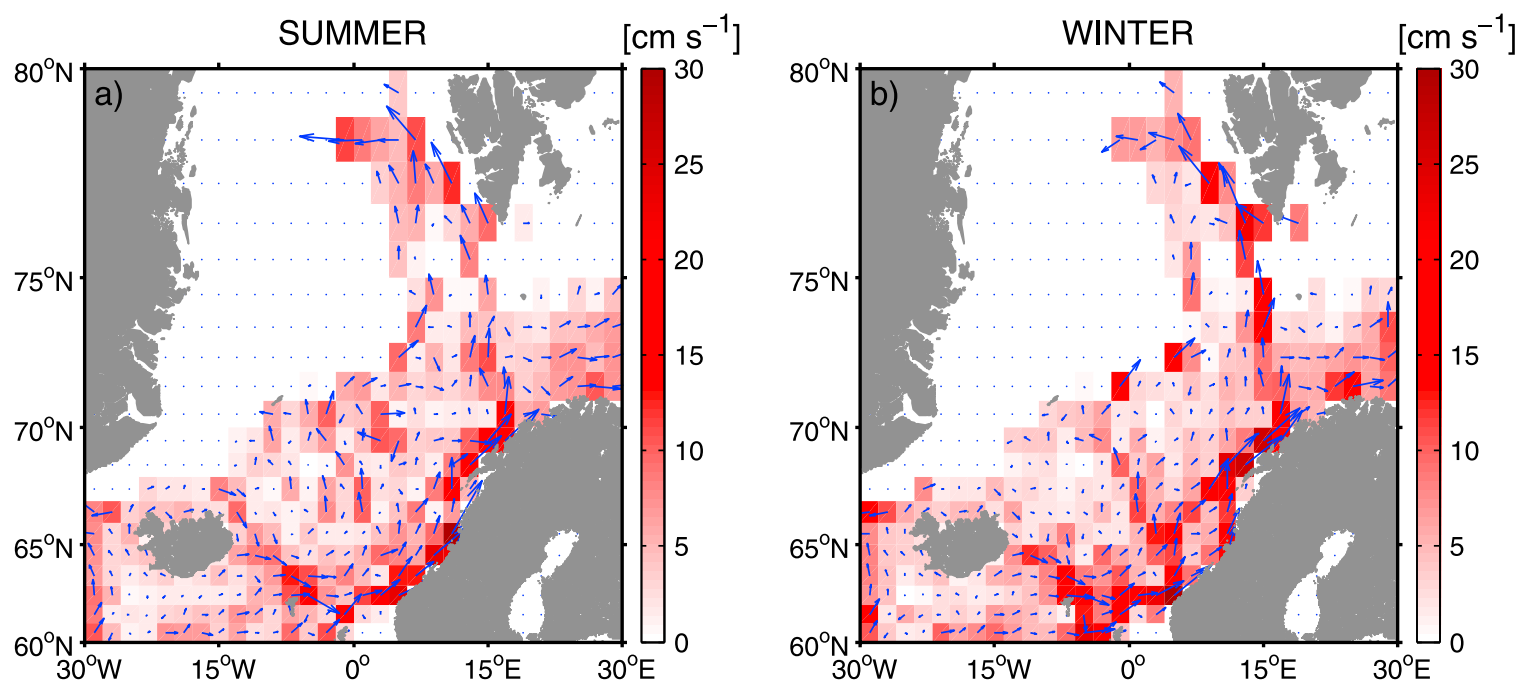

Figure 10. Mean velocity vectors computed from drogued observations in $2^{\circ}$ longitude by $1^{\circ}$ latitude bins for (a) summer and (b) winter seasons. Only bins that are present both seasons are shown. 
DIFFERENCE OF MEAN VELOCITY, SEASONAL

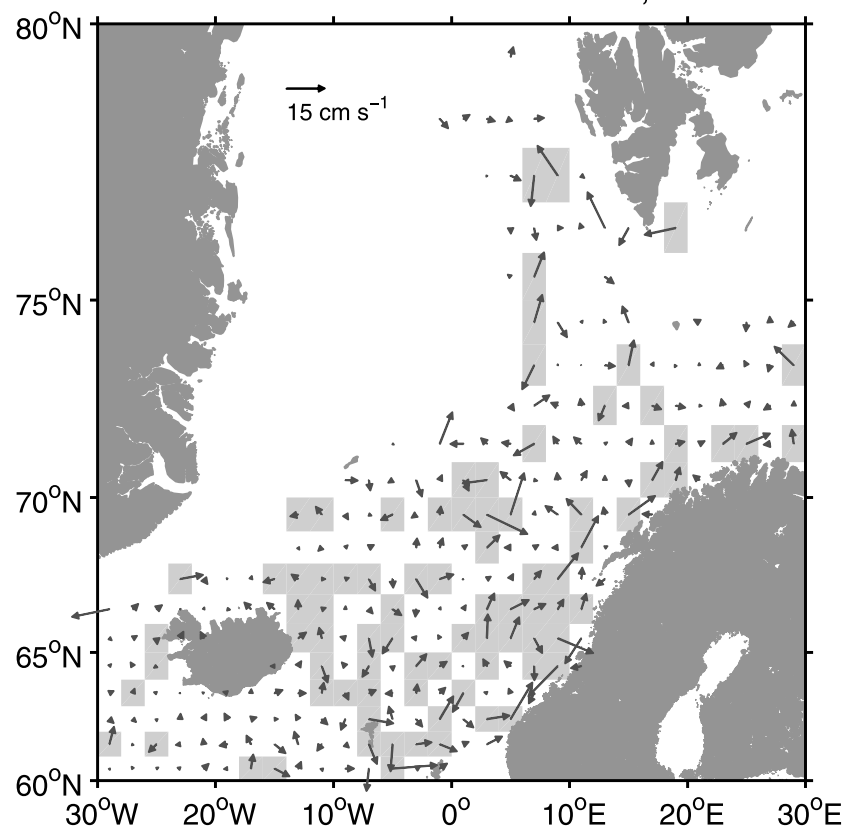

Figure 11. Seasonal variation of the pseudo-Eulerian nearsurface currents calculated as the difference between winter and summer. The shading indicates areas where the difference is statistically significant to the $95 \%$ level based on the vectorial $t$ test described by Garraffo et al. [2001].

In contrast, the winter sampling comes from drifters deployed outside the basin which subsequently passed through. These drifters evidently were not entrained by the eddy, but simply skirted it.

[37] The eddy kinetic energies for the summer and winter seasons are shown in Figure 12; Figure 13 shows the difference in EKE between winter and summer in bins where the variance is statistically different between the seasons at the $95 \%$ level. The results suggest the variability is greater

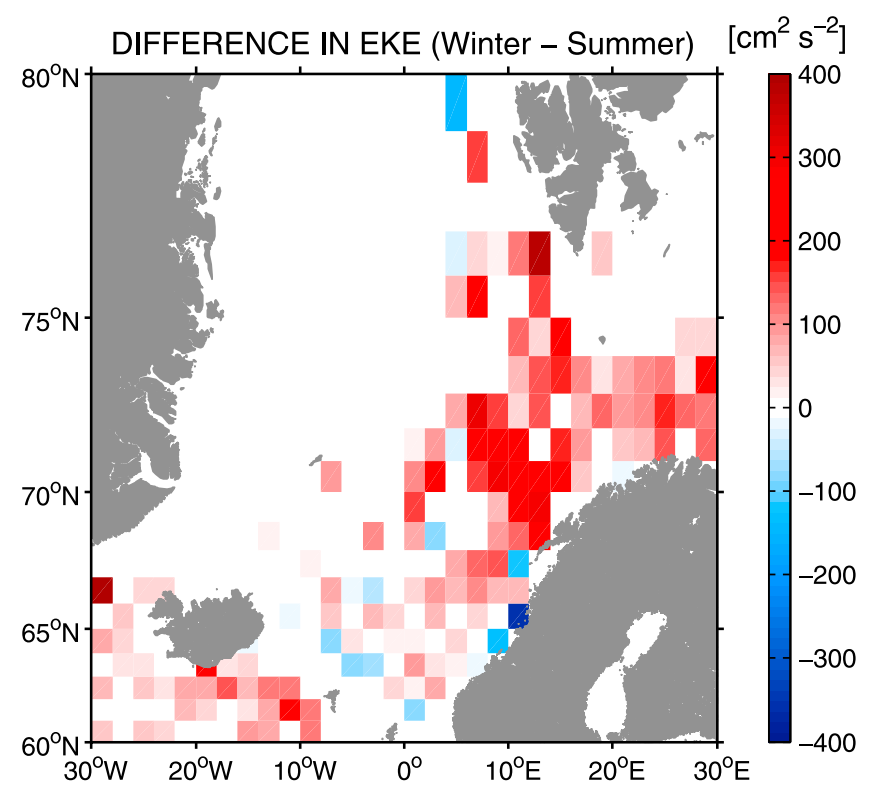

Figure 13. Difference in EKE between winter and summer (winter minus summer), shown in bins where the difference in variance is statistically significant to the $95 \%$ level based on the $F$ test.

in winter in particular regions, most noticeably in the Lofoten Basin. The difference moreover appear to be significant in many bins.

[38] Now consider the changes between the 1990s and the 2000s. The mean circulations for both periods are shown in Figure 14 and the difference field is shown in Figure 15. There are regional variations in the fields, but these are mostly insignificant or related to differences in sampling, for example west of Spitsbergen. The anticyclonic recirculation in the Lofoten Basin seen in Figure 6 is apparent during the 2000s but not the 1990s; however, this also is likely the result of the targeted deployments in the Lofoten during the summer of 2009 .
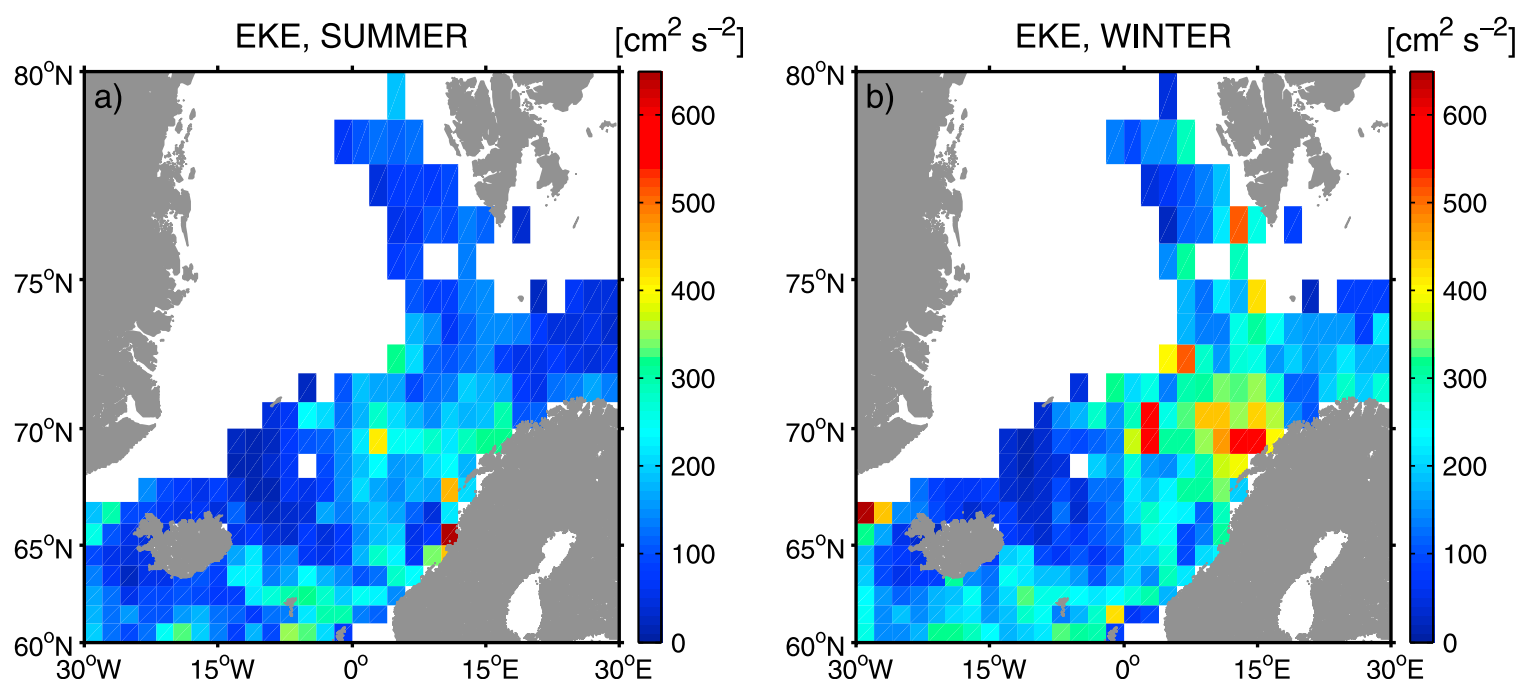

Figure 12. Distribution of the fluctuation or eddy kinetic energy calculated from drifter data for (a) summer and (b) winter seasons in $2^{\circ}$ longitude by $1^{\circ}$ latitude bins. Only bins that are present both seasons are shown. 

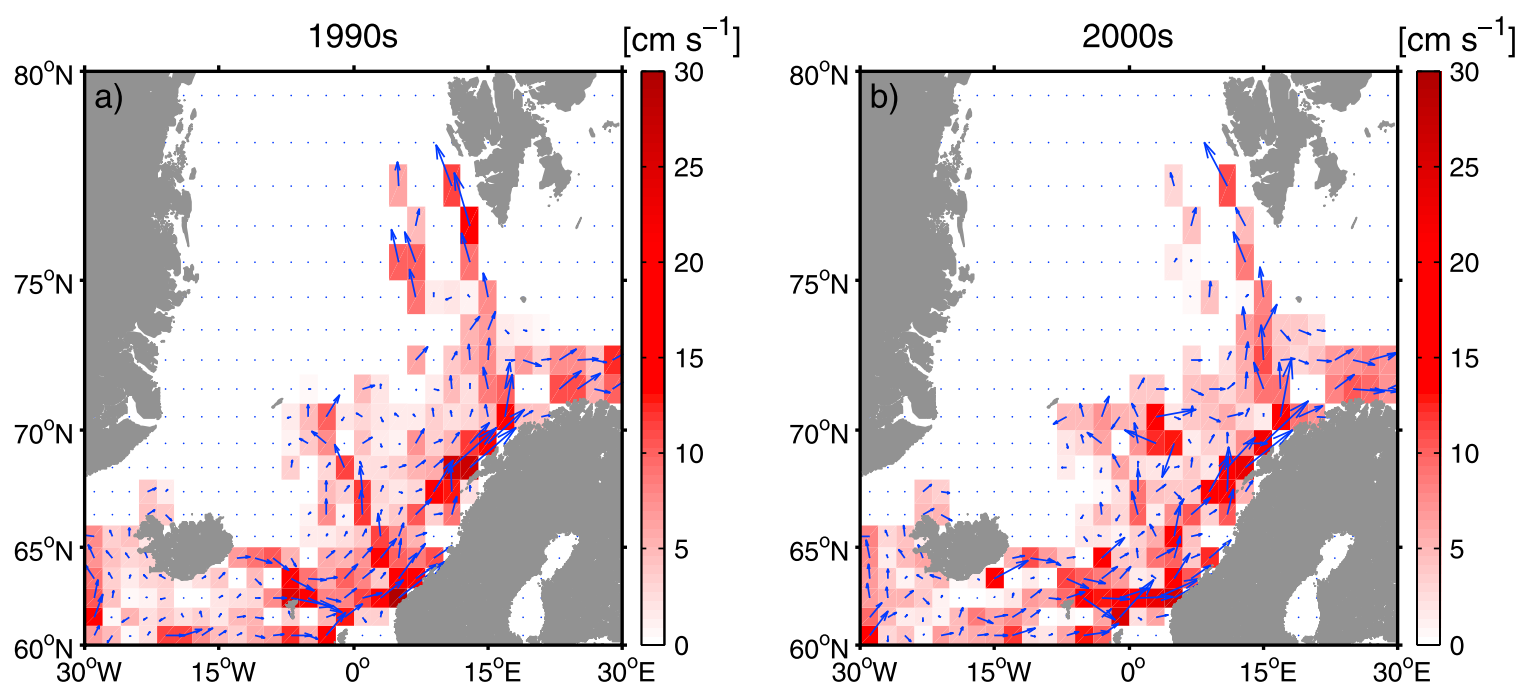

Figure 14. Mean velocity vectors computed from drogued observations in $2^{\circ}$ longitude by $1^{\circ}$ latitude bins for (a) 1991-1998 and (b) 1999-2009. Only bins that are present both decades are shown.

[39] The eddy kinetic energy for the two periods are shown in Figure 16 and the difference between the decades is shown in Figure 17, in bins where the differences are significant. In several regions, there is more variability in the 2000s than in the 1990s; in the Lofoten region and near the Iceland-Faroe ridge. However, the significance is variable. We do not see for instance that the changes over the entire Lofoten region are significant.

[40] Because the data coverage varies between seasons and decades, it is advantageous to average the data over larger regions. For this, we use the five regions defined earlier. We calculate the means and variances for the winter and summer seasons of each year. This yields a time series over the entire time period for each region.

[41] The velocities, averaged in this way, are shown in Figure 18. The number of observations used in each average is shown in Figure 19. Only seasons with at least 25 observations are shown.

[42] In the IFF (Iceland-Faroe Front) region, the mean zonal velocity is generally positive and the mean meridional velocity negative, indicating a flow to the southeast. There is an indication of seasonal variability in the zonal velocity in the early 90s. However, at later times the seasonality is less apparent and it is not seen in the meridional velocity. In addition, the means in the 2 decades are not different, within the errors. The zonal velocity appears to weaken after 2007, but the error bars are larger; so the changes are not significant. We conclude that the mean velocities in the IFF region have little seasonality and have not changed between the 2 decades.

[43] The situation is much the same in the Iceland Plateau, Norwegian Basin and Lofoten Basin regions. The seasonality is weak to nonexistent and the means are essentially unchanged between the decades. The periods where the velocities deviate strongly from the means are also periods where there are few observations, for example during 1996 in the IP region. While the error bars are often small enough so that the deviations appear significant, this reflects that the few drifters present had similar velocities. But because there are so few observations, the region was not well sampled and the mean thus unreliable.

[44] The region which stands out here is the NwAC. This also happens to be the best-sampled region, with the number of observations frequently exceeding 5000 in a season (Figure 19). The means are positive in both directions, indicating a flow toward the northeast. And while the decadal



Figure 15. Interannual variation of the pseudo-Eulerian near-surface currents calculated as the difference between 1999-2009 and 1991-1998. Only bins with at least 25 observations during both seasons are shown. The shading indicates areas where the difference is statistically significant to the $95 \%$ level based on the vectorial $t$ test described by Garraffo et al. [2001]. 

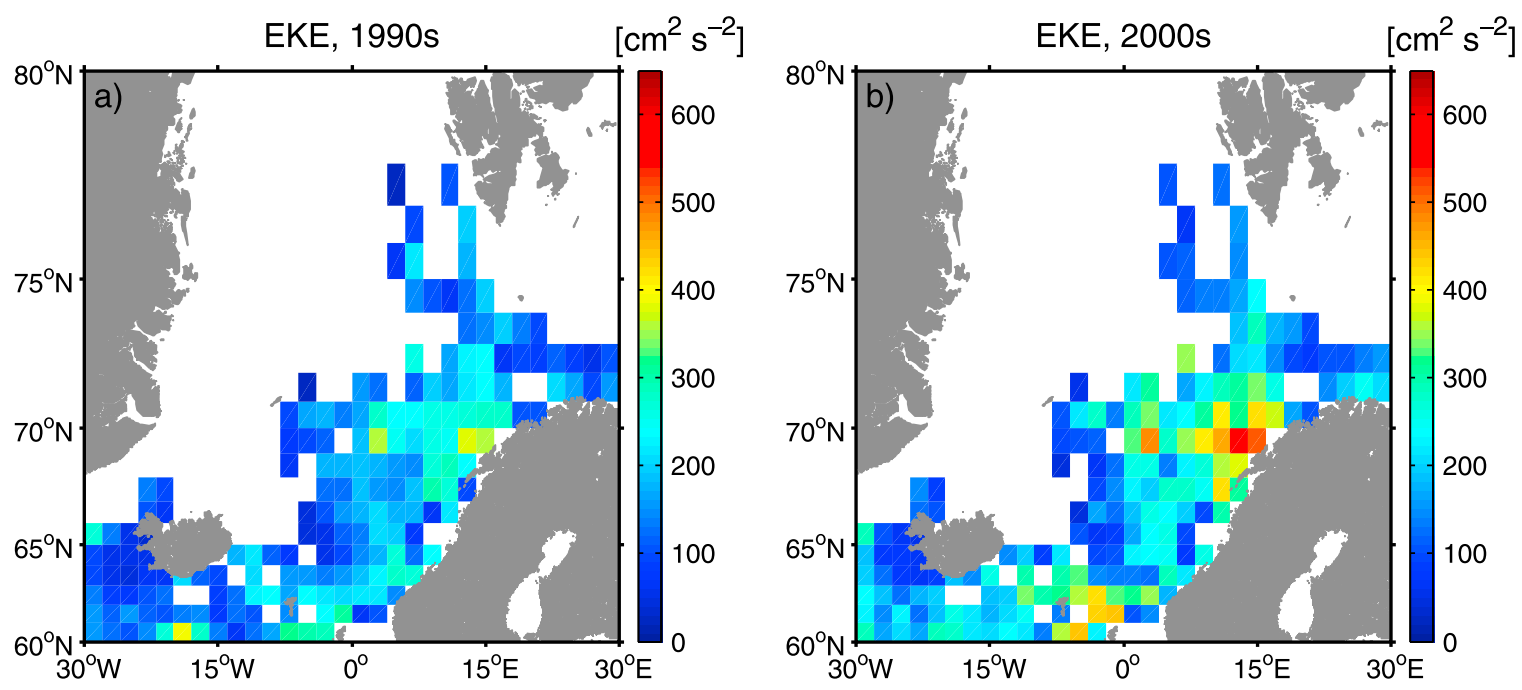

Figure 16. Distribution of the fluctuation or eddy kinetic energy calculated from drifter data for the periods (a) 1991-1998 and (b) 1999-2009 in $2^{\circ}$ longitude by $1^{\circ}$ latitude bins. Only bins that are present both decades are shown.

means aren't significantly different, there is a pronounced sawtooth pattern in both curves, indicating strong seasonality. The winter means are typically about $20 \%$ greater than the summer means.

[45] Thus Figure 18 suggests that the mean velocities do not change significantly between the 2 decades, nor do they vary consistently with season. The exception is the NwAC region, which shows a consistent intensification in winter. The NwAC region primarily reflects the eastern branch of the inflow, so that inflow is stronger in the wintertime. This is consistent with results by Orvik and Skagseth [2005] based on current meter data from the Svinøy Section.

[46] Now consider the region-averaged variances, shown in Figure 20. In the IFF region, the variances are fairly constant during the $1990 \mathrm{~s}$, with the error bars in most seasons overlapping the average for the decade. There are instances both when the winter variance is greater than the preceding summer and vice versa. Thus the variance don't change consistently with season. The season-to-season variation increases markedly during the 2000s, and the decadal averages are higher than in the 1990s. Thus at first glance, the region appears to have undergone a substantial change during the second decade. However, the observations during this period also have a seasonal variation, with fewer observations in summer than winter (Figure 19). Moreover, the error bars have increased dramatically during this period, so that many of the seasonal averages are not different from the decadal average during the 1990s. Thus while there might be an actual change in the variances in the 2000 s, it is just as likely that the data from that decade are yielding less stable averages than earlier. We conclude that there is no significant evidence for either seasonality or decadal changes in the variances here.

[47] Similar comments apply in the other four regions. The variances are not significantly different between the decades and the seasonality is weak. Instances with strong variations can generally be traced to having few observations, for example the summer 1999 maximum in the Norwegian Basin or the winter 2005 maximum in the NwAC.
[48] These regional time series shed light on the maps in Figures 10-15. The mean velocities in Figure 10 are greater in winter in the eastern branch of the NwAC, but not significantly different elsewhere. The mean velocities in Figure 14 on the other hand are not appreciably different. Figures 12 and 16 suggest the variability near the Lofoten Islands is greater in winter and in the 2000s. But the results of Figure 20 imply these higher values likely stem from several isolated periods (the winters of 2005 and 2006) when there were few observations. Thus the differences in both Figures 12 and 16 are probably insignificant.

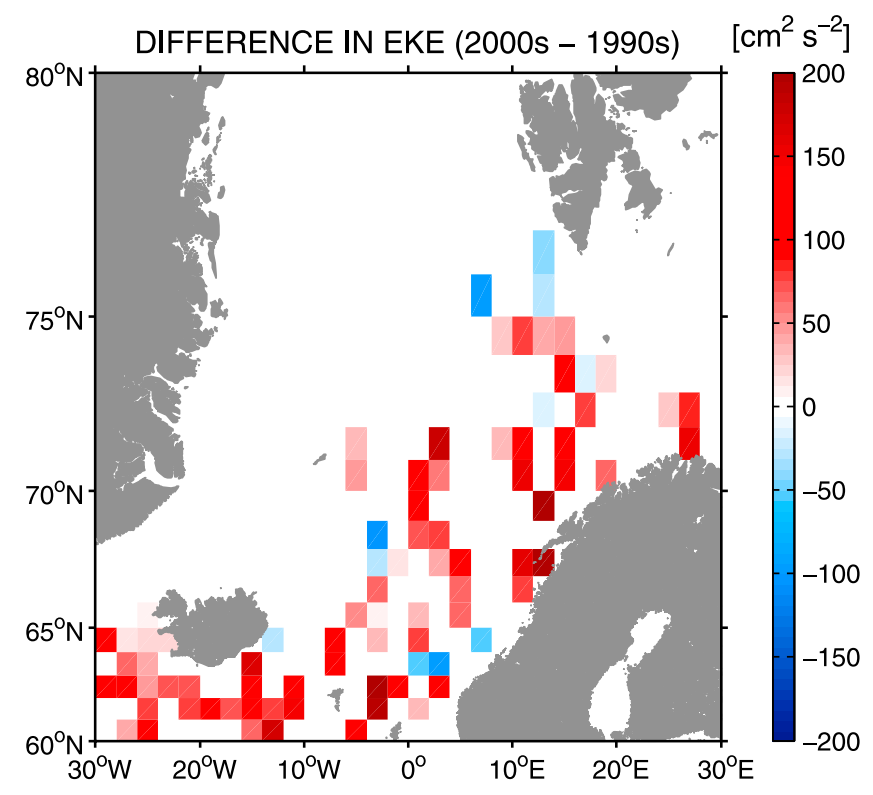

Figure 17. Difference in EKE between the 2000s and the 1990s (2000s minus 1990s), shown in bins where the difference in variance is statistically significant to the $95 \%$ level based on the $F$ test. 

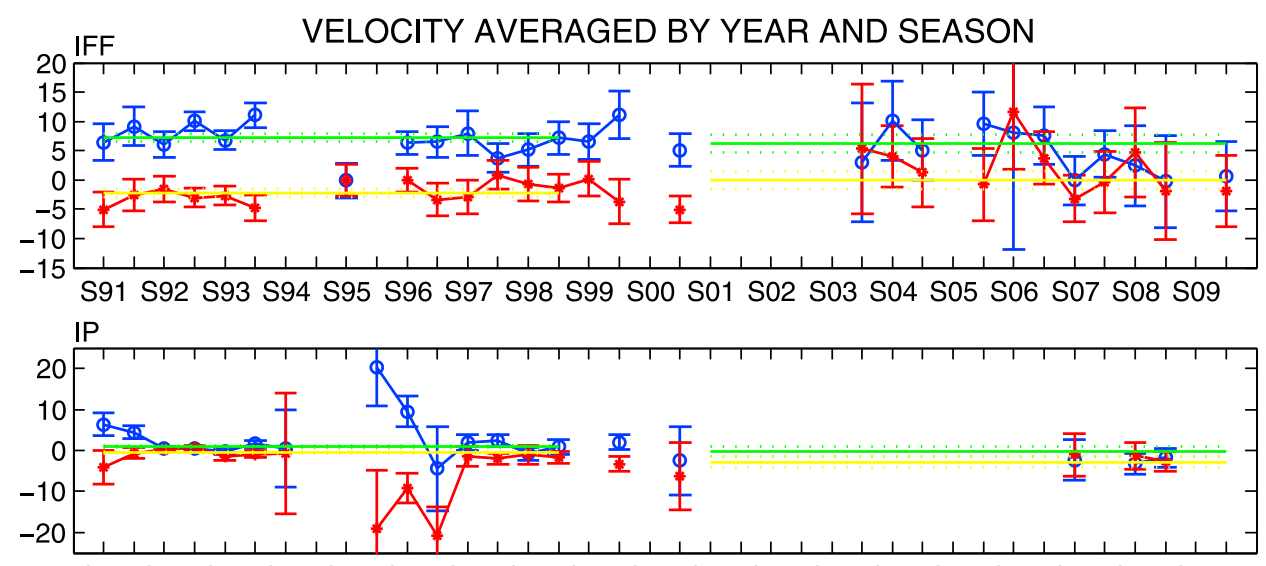

S91 S92 S93 S94 S95 S96 S97 S98 S99 S00 S01 S02 S03 S04 S05 S06 S07 S08 S09


NwAC



Figure 18. Velocity averaged by year and season for the five domains. The blue curves indicate the mean zonal velocity and the red indicate the meridional velocity. The means for the 2 decades with errors are indicated by the horizontal lines, green for zonal and yellow for meridional. The errors show the $95 \%$ confidence level based on a Student's $t$ distribution with $n^{*}-1$ degrees of freedom.

[49] The Lagrangian length and time scales are given in Tables A2-A5 in Appendix A. The time scales are remarkably consistent and do not vary with season or decade. In most regions the time scale is between 1 and 1.2 days. Likewise, the length scales do not vary seasonally, except in the Lofoten where they are slightly larger in winter. In most cases, the length scales are between 10 and $20 \mathrm{~km}$.

\section{Summary and Discussion}

[50] Satellite-tracked drifters drogued at $15 \mathrm{~m}$ depth have been used to examine the near-surface mean currents and variability in the eastern Nordic Seas from June 1991 to December 2009. The data distribution is almost uniform with respect to season permitting an assessment of seasonal variability. Furthermore, since the sampling spans a 20 year period, we were able to make a rough assessment of interdecadal changes.
[51] With all the new data added, the general structure of the mean field remains the same: The mean flow is dominated by the NwAC, which has two branches. Both are strongly steered by topography. The NwCC is also resolved, near the Norwegian coast, and this merges with the inner branch of the NwAC in several locations. The strongest measured currents were approximately $100 \mathrm{~cm} \mathrm{~s}^{-1}$, in the vicinity of the Lofoten Basin and Islands. The latter is a region with steep topography, and the current accelerates where the isobaths constrict. There is an anticyclonic standing eddy in the Lofoten Basin, as noted previously [Ivanov and Korablev, 1995; Köhl, 2007]. This was particularly apparent during the POLEWARD period, in the summer, when there was a targeted deployment in the Lofoten Basin in 2009.

[52] The eddy field is thoroughly inhomogeneous. The variability is greatest near the main branches of the NwAC, suggesting there are continually spawning eddies through 



Figure 19. Number of observations by year and season for the five domains. Note the different scaling on the y axis.

instability. The variability is greatest of all in the Lofoten Basin, where the variances exceed $600 \mathrm{~cm}^{2} \mathrm{~s}^{-2}$. The Lagrangian time scales are remarkably consistent over the whole region, having values typically from 1 to 1.5 days. Thus the diffusivities resemble the variances, with the largest values occurring in the Lofoten Basin. Averaged over the Basin, the diffusivities are on the order of $3 \times 10^{7} \mathrm{~cm}^{2} \mathrm{~s}^{-1}$.

[53] The elevated variability in the Lofoten area appears to stem from eddies propagating into the basin from the slope region, where they are generated. Such an effect was suggested by Poulain et al. [1996]. It has also been inferred in modeling studies [Spall, 2004; Köhl, 2007] and from subsurface float data [Rossby et al., 2009].

[54] Our length scales of 10-20 km are consistent with but on the low end of the range (10-40 km) inferred by Poulain et al. [1996]. The length scales nevertheless are like those inferred by LaCasce [2005] (10-20 km) using current meters over the western Norwegian shelf and slope. The deformation radius here is on the order of $10 \mathrm{~km}$, so deformation scale eddies are a natural candidate to explain the variability. Krauss et al. [1990] and Stammer [1997] maintain that eddy scales in the North Atlantic scale with the deformation radius, and the present result is consistent.

[55] The means and variances exhibit some season to season variations throughout the region. However the only mean field which shows consistent seasonality is the NwAC itself; this strengthens by about $20 \%$ in winter. The results are thus consistent with previous results by Orvik and Skagseth [2005] and Jakobsen et al. [2003], who found that the main currents strengthened by about $5 \mathrm{~cm} \mathrm{~s}^{-1}$ in winter (corresponding to about $20 \%$ of the mean). There is no evidence that the fluctuating field does change consistently between seasons.

[56] While there are instances of the EKE in a given region increasing dramatically during a given season or year (see for instance the NwAC region 2005 in Figure 20), the 

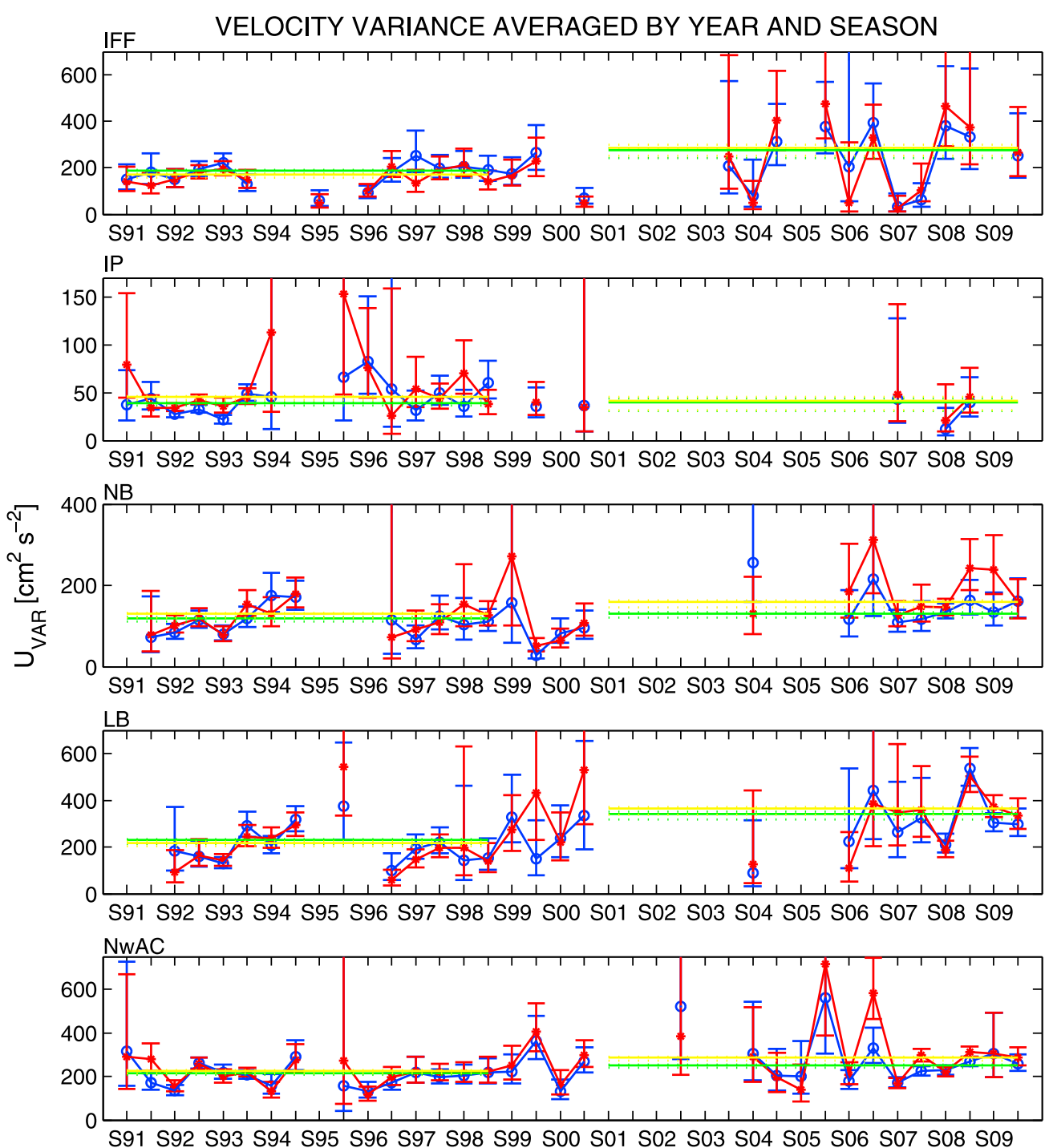

Figure 20. Velocity variance averaged by year and season for the five domains. The blue curves indicate the mean zonal velocity variance and the red the indicate the meridional velocity variance. The means for the 2 decades with errors are indicated by the horizontal lines, green for zonal and yellow for meridional. The errors show the $95 \%$ confidence level based on a chi-square probability distribution with $n^{*}-1$ degrees of freedom.

errors are also proportionally larger. So we cannot reject the possibility that the fluctuations during such periods is in fact the same on average as during the more quiescent periods.

[57] Previously, Isachsen et al. [2003] found that the circulation in the Nordic Seas gyres (the Lofoten, Norwegian and Greenland gyres) intensifies in winter. This occurs as the wind forcing is greater in winter, driving a stronger along-isobath flow in regions of closed topographic contours. The only basin that is sampled well enough by the drifters to possibly detect this is the Lofoten Basin. In that basin we do indeed find evidence of increased EKE in the winter (Figure 12), but not of the mean flow. On the other hand, the variances averaged by year and season (Figure 20) shows weak seasonality. Where the variance is greater in the Lofoten in winter, the errors are also greater. Thus we cannot resolve a significant difference with confidence.

[58] Recently Hakkinen and Rhines [2009] suggested that the variability along the path of the NwAC has increased in the last decade, as compared to the 1990s, based on altimeter data. There is no evidence in the drifter data set of such a strengthening of the NwAC. The averages of the drifterderived statistics are remarkably similar in the two sampled decades. In regions where there appears to be greater variability in one of the decades, the errors are proportionally larger. We consider it likely that those differences are due to variations in the drifter coverage rather than an actual change in the currents.

\section{Appendix A: Lagrangian Statistics}

[59] The characteristic timescale of dispersion is the Lagrangian eddy timescale $T_{L}$

$$
T_{L}=\int_{0}^{\infty} d \tau R .
$$


Table A1. Lagrangian Statistics Estimated as a Mean Over 6-10 Days for the Period 1991-2009

\begin{tabular}{|c|c|c|c|c|c|c|c|c|c|}
\hline Region & Number of Observations & $\left\langle u_{u u}^{\prime 2}\right\rangle$ & $\left\langle u_{v v}^{\prime 2}\right\rangle$ & $\left\langle\kappa_{u u}\right\rangle$ & $\left\langle\kappa_{v v}\right\rangle$ & $L_{u u}(\mathrm{~km})$ & $L_{v v}(\mathrm{~km})$ & $T_{u u}$ (days) & $T_{v v}$ (days) \\
\hline IFF & 19,366 & 183.1 & 179.8 & 2.25 & 1.64 & 16 & 12 & 1.2 & 0.9 \\
\hline IP & 17,686 & 35.9 & 37.7 & 0.68 & 0.66 & 9 & 9 & 1.5 & 1.3 \\
\hline NB & 22,718 & 113.7 & 123.4 & 1.45 & 2.38 & 12 & 18 & 1.2 & 1.5 \\
\hline LB & 25,433 & 257.0 & 264.5 & 3.64 & 2.65 & 20 & 15 & 1.3 & 1.0 \\
\hline NwAC & 73,035 & 198.7 & 207.5 & 2.38 & 2.63 & 16 & 18 & 1.2 & 1.3 \\
\hline
\end{tabular}

${ }^{\mathrm{a}}$ The velocity variances $\left(u^{\prime 2}\right)$ and diffusivities $(\kappa)$ are given in $\mathrm{cm}^{2} \mathrm{~s}^{-2}$ and $10^{7} \mathrm{~cm}^{2} \mathrm{~s}^{-1}$, respectively.

Table A2. Lagrangian Statistics Estimated as a Mean Over 6-10 Days for Summer Season ${ }^{\text {a }}$

\begin{tabular}{lccccccccc}
\hline Region & Number of Observations & $\left\langle u_{u u}^{\prime 2}\right\rangle$ & $\left\langle u_{v v}^{\prime 2}\right\rangle$ & $\left\langle\kappa_{u u}\right\rangle$ & $\left\langle\kappa_{v v}\right\rangle$ & $L_{u u}(\mathrm{~km})$ & $L_{v v}(\mathrm{~km})$ & $T_{u u}(\mathrm{days})$ & $T_{v v}(\mathrm{days})$ \\
\hline IFF & 10,158 & 173.6 & 160.6 & 1.86 & 2.05 & 13 & 16 & 1.1 & 1.4 \\
IP & 8605 & 32.0 & 35.8 & 0.81 & 0.54 & 10 & 7 & 1.5 & 1.0 \\
NB & 12,424 & 111.0 & 115.7 & 1.17 & 1.62 & 11 & 13 & 1.1 \\
LB & 13,951 & 192.9 & 214.3 & 2.31 & 2.69 & 15 & 17 & 1.2 & 1.2 \\
NwAC & 28,979 & 186.6 & 183.0 & 2.18 & 1.90 & 15 & 13 & 1.2 & 1.0 \\
\hline
\end{tabular}

${ }^{\text {a }}$ The velocity variances $\left(u^{\prime 2}\right)$ and diffusivities $(\kappa)$ are given in $\mathrm{cm}^{2} \mathrm{~s}^{-2}$ and $10^{7} \mathrm{~cm}^{2} \mathrm{~s}^{-1}$, respectively.

Table A3. Lagrangian Statistics Estimated as a Mean Over 6-10 Days for Winter Season ${ }^{\mathrm{a}}$

\begin{tabular}{lccccccccc}
\hline Region & Number of Observations & $\left\langle u_{u u}^{\prime 2}\right\rangle$ & $\left\langle u_{v v}^{\prime 2}\right\rangle$ & $\left\langle\kappa_{u u}\right\rangle$ & $\left\langle\kappa_{v v}\right\rangle$ & $L_{u u}(\mathrm{~km})$ & $L_{v v}(\mathrm{~km})$ & $T_{u u}($ days $)$ & $T_{v v}(\mathrm{days})$ \\
\hline IFF & 9208 & 193.6 & 201.1 & 2.42 & 2.24 & 16 & 15 & 1.2 & 1.1 \\
IP & 9081 & 39.6 & 39.5 & 0.59 & 0.61 & 8 & 8 & 1.2 & 1.2 \\
NB & 10,294 & 117.0 & 132.7 & 1.25 & 1.58 & 11 & 12 & 1.0 \\
LB & 11,482 & 334.9 & 325.4 & 4.27 & 3.64 & 21 & 19 & 1.2 & 1.2 \\
NwAC & 44,056 & 206.7 & 223.5 & 2.31 & 2.39 & 16 & 16 & 1.2 & 1.2 \\
\hline
\end{tabular}

${ }^{\mathrm{a}}$ The velocity variances $\left(u^{\prime 2}\right)$ and diffusivities $(\kappa)$ are given in $\mathrm{cm}^{2} \mathrm{~s}^{-2}$ and $10^{7} \mathrm{~cm}^{2} \mathrm{~s}^{-1}$, respectively.

Table A4. Lagrangian Statistics Estimated as a Mean Over 6-10 Days for the Period 1991-1998

\begin{tabular}{lccccccccc}
\hline Region & Number of Observations & $\left\langle u_{u u}^{\prime 2}\right\rangle$ & $\left\langle u_{v v}^{\prime 2}\right\rangle$ & $\left\langle\kappa_{u u}\right\rangle$ & $\left\langle\kappa_{v v}\right\rangle$ & $L_{u u}(\mathrm{~km})$ & $L_{v v}(\mathrm{~km})$ & $T_{u u}(\mathrm{days})$ & $T_{v v}(\mathrm{days})$ \\
\hline IFF & 15,159 & 161.9 & 155.7 & 1.89 & 1.68 & 15 & 13 & 1.3 & 1.2 \\
IP & 16,342 & 34.3 & 35.7 & 0.46 & 0.58 & 7 & 8 & 1.0 & 1.2 \\
NB & 11,642 & 107.4 & 108.5 & 1.26 & 1.60 & 11 & 12 & 1.1 \\
LB & 12,257 & 224.5 & 217.7 & 2.73 & 2.27 & 16 & 15 & 1.1 \\
NwAC & 32,315 & 181.9 & 175.1 & 2.28 & 2.04 & 16 & 15 & 1.2 & 1.1 \\
\hline
\end{tabular}

${ }^{a}$ The velocity variances $\left(u^{\prime 2}\right)$ and diffusivities $(\kappa)$ are given in $\mathrm{cm}^{2} \mathrm{~s}^{-2}$ and $10^{7} \mathrm{~cm}^{2} \mathrm{~s}^{-1}$, respectively.

Table A5. Lagrangian Statistics Estimated as a Mean Over 6-10 Days for the Period 1999-2009 ${ }^{\text {a }}$

\begin{tabular}{lccccccccc}
\hline Region & Number of Observations & $\left\langle u_{u u}^{\prime 2}\right\rangle$ & $\left\langle u_{v v}^{\prime 2}\right\rangle$ & $\left\langle\kappa_{u u}\right\rangle$ & $\left\langle\kappa_{v v}\right\rangle$ & $L_{u u}(\mathrm{~km})$ & $L_{v v}(\mathrm{~km})$ & $T_{u u}($ days $)$ & $T_{v v}(\mathrm{days})$ \\
\hline IFF & 4207 & 284.4 & 302.6 & 4.32 & 2.79 & 23 & 15 & 1.4 & 0.9 \\
IP & 1344 & 56.0 & 61.8 & 0.54 & 1.26 & 8 & 14 & 1.2 & 1.9 \\
NB & 11,076 & 120.0 & 139.1 & 1.58 & 2.44 & 13 & 18 & 1.2 & 1.5 \\
LB & 13,176 & 287.3 & 308.5 & 3.76 & 2.92 & 20 & 16 & 1.2 & 1.2 \\
NwAC & 40,720 & 212.0 & 233.1 & 2.42 & 2.99 & 16 & 19 & 1.4 \\
\hline
\end{tabular}

${ }^{\mathrm{a}}$ The velocity variances $\left(u^{\prime 2}\right)$ and diffusivities $(\kappa)$ are given in $\mathrm{cm}^{2} \mathrm{~s}^{-2}$ and $10^{7} \mathrm{~cm}^{2} \mathrm{~s}^{-1}$, respectively. 
Table A6. Trajectory Segments Used for Estimating the Lagrangian Statistics for 1991-2009

\begin{tabular}{lccccc}
\hline & \multirow{2}{*}{$\begin{array}{c}\text { Number } \\
\text { Region }\end{array}$} & \multicolumn{4}{c}{ Length (days) } \\
\cline { 3 - 6 } of Segments & Minimum & Maximum & Median & Mean \\
\hline IFF & 125 & 4 & 133 & 32 & 38 \\
IP & 46 & 5 & 324 & 59 & 96 \\
NB & 142 & 4 & 259 & 18 & 39 \\
LB & 182 & 4 & 334 & 18 & 34 \\
NwAC & 373 & 4 & 303 & 32 & 48 \\
\hline
\end{tabular}

[60] This is the lag over which a particle's speed stays strongly correlated with itself. Because the particle moves at a characteristic eddy speed $u^{\prime}$ given by the standard deviation of $u$, this timescale corresponds to a distance

$$
L_{L}=u^{\prime} T_{L}
$$

called the Lagrangian eddy length scale [Lumpkin et al., 2001].

[61] The results of the Lagrangian statistics for 19912009, summer and winter seasons, and for 1991-1998 and 1999-2009 are shown in Tables A1-A5. The diffusivities and the time and length scales are found in the last columns.

[62] The number of trajectory segments along with minimum, maximum, median and mean segment length for each of the five regions are listed in Table A6. The segments were used for estimating the Lagrangian statistics for the period 1991-2009.

[63] Acknowledgments. This study is part of the POLEWARD project, funded by the Norwegian Research Council Norklima program (grant 178559/S30). The data set was processed by the AOML-NOAA Global Drifter Program and is available from their Web site at http://www.aoml. noaa.gov. We thank two anonymous reviewers for useful comments and suggestions.

\section{References}

Chelton, D. B., R. A. Deszoeke, M. G. Schlax, K. El Naggar, and N. Siwertz (1998), Geographical variability of the first baroclinic Rossby radius of deformation, J. Phys. Oceanogr., 108(3), 433-460.

Davis, R. E. (1983), Oceanic property transport, Lagrangian particle statistics, and their prediction, J. Mar. Res., 41(1), 163-194.

Davis, R. E. (1991), Observing the general circulation with floats, Deep Sea Res., 38, suppl. 1, S531-S571.

Dietrich, G., K. Kalle, and F. Ostapoff (1980), General Oceanography: An Introduction, Wiley, New York.

Emery, W. J., and R. E. Thomson (2001), Data Analysis Methods in Physical Oceanography, Elsevier Sci., Amsterdam.

Fratantoni, D. M. (2001), North Atlantic surface circulation during the 1990's observed with satellite-tracked drifters, J. Geophys. Res., 106(C10), 22,067-22,093.

Freeland, H. J., P. B. Rhines, and T. Rossby (1975), Statistical observations of the trajectories of neutrally buoyant floats in the North Atlantic, J. Mar. Res., 33(3), 383-404.

Garraffo, Z. D., A. J. Mariano, A. Griffa, C. Veneziani, and E. P. Chassignet (2001), Lagrangian data in a high-resolution numerical simulation of the North Atlantic: Part I. Comparison with in situ drifter data, J. Mar. Syst., $29(1-4), 157-176$

Hakkinen, S., and P. B. Rhines (2009), Shifting surface currents in the northern North Atlantic Ocean, J. Geophys. Res., 114, C04005, doi:10.1029/2008JC004883.

Hansen, D. V., and P.-M. Poulain (1996), Quality control and interpolations of WOCE-TOGA drifter data, J. Atmos. Oceanic Technol., 13(4), 900-909.
Hurrell, J. W. (1995), Decadal trends in the North Atlantic Oscillation: Regional temperatures and precipitation, Science, 269(5224), 676-679.

Isachsen, P. E., J. H. LaCasce, C. Mauritzen, and S. Hakkinen (2003), Wind-driven variability of the large-scale recirculating flow in the Nordic Seas and Arctic Ocean, J. Phys. Oceanogr., 33(12), 2534-2550.

Ivanov, V. V., and A. A. Korablev (1995), Formation and regeneration of the pycnocline lens in the Norwegian Sea, Russ. Meteorol. Hydrol., 9, $62-69$

Jakobsen, P. K., M. H. Ribergaard, D. Quadfasel, T. Schmith, and C. W. Hughes (2003), Near-surface circulation in the northern North Atlantic as inferred from Lagrangian drifters: Variability from the mesoscale to interannual, J. Geophys. Res., 108(C8), 3251, doi:10.1029/ 2002JC001554

Krauss, W., and C. W. Böning (1987), Lagrangian properties of eddy fields in the northern North Atlantic as deduced from satellite-tracked buoys, J. Mar. Res., 45(2), 259-291.

Krauss, W., R. Döscher, A. Lehmann, and T. Viehoff (1990), On eddy scales in the eastern and northern North Atlantic Ocean as a function of latitude, J. Geophys. Res., 95(18), 18,049-18,056.

Koszalka, I. M., and J. H. LaCasce (2010), Lagrangian analysis by clustering, Ocean Dyn., 60(4), 957-972.

Koszalka, I. M., J. H. LaCasce, M. Andersson, K. A. Orvik, and C. Mauritzen (2011), Surface circulation in the Nordic Seas from clustered drifters, Deep Sea Res. Part I, 58, 468-485, doi:10.1016/j. dsr.2011.01.007.

Köhl, A. (2007), Generation and stability of a quasi-permanent vortex in the Lofoten Basin, J. Phys. Oceanogr., 37(11), 2637-2651.

LaCasce, J. H. (2005), Statistics of low frequency currents over the western Norwegian shelf and slope, part I: Current meters, Ocean Dyn., 55(3), 213-221

LaCasce, J. H. (2008), Statistics from Lagrangian observations, Prog. Oceanogr., 77(1), 1-29.

Lumpkin, R. (2003), Decomposition of surface drifter observations in the Atlantic Ocean, Geophys. Res. Lett., 30(14), 1753, doi:10.1029/ 2003GL017519.

Lumpkin, R., and M. Pazos (2006), Measuring surface currents with Surface Velocity Program drifters: The instrument, its data, and some recent results, in Lagrangian Analysis and Prediction of Coastal and Ocean Dynamics, edited by N. Griffa et al., pp. 39-67, Cambridge Univ. Press, Cambridge, U. K.

Lumpkin, R., A. M. Treguier, and K. Speer (2001), Lagrangian eddy scales in the northern Atlantic Ocean, J. Phys. Oceanogr., 32(9), 2425-2440.

Mauritzen, C. (1996), Production of dense overflow waters feeding the North Atlantic across the Greenland-Scotland Ridge. Part 1: Evidence for a revised circulation scheme, Deep Sea Res. Part I, 43(6), 769-806.

Niiler, P. P., R. E. Davis, and H. J. White (1987), Water-following characteristics of a mixed layer drifter, Deep Sea Res. Part A, 34(11), 1867-1881.

Orvik, K. A. (2004), The deepening of the Atlantic water in the Lofoten Basin of the Norwegian Sea, demonstrated by using an active reduced gravity model, Geophys. Res. Lett., 31, L01306, doi:10.1029/ 2003GL018687.

Orvik, K. A., and P. P. Niiler (2002), Major pathways of the Atlantic water in the northern North Atlantic and Nordic Seas toward Arctic, Geophys. Res. Lett., 29(19), 1896, doi:10.1029/2002GL015002.

Orvik, K. A., and Ø. Skagseth (2003), The impact of the wind stress curl in the North Atlantic on the Atlantic inflow to the Norwegian Sea toward the Arctic, Geophys. Res. Lett., 30(17), 1884, doi:10.1029/ 2003GL017932.

Orvik, K. A., and Ø. Skagseth (2005), Heat flux variations in the eastern Norwegian Atlantic Current toward the Arctic from moored instruments, 1995-2005, Geophys. Res. Lett., 32, L14610, doi:10.1029/ 2005 GL023487.

Orvik, K. A., Ø. Skagseth, and M. Mork (2001), Atlantic inflow to the Nordic Seas: Current structure and volume fluxes from moored current meters, VM-ADCP and SeaSoar-CTD observations, 1995-1999, Deep Sea Res. Part I, 48(4), 937-957.

Poulain, P.-M., and P. P. Niiler (1989), Statistical analysis of the surface circulation in the California Current System using satellite-tracked drifters, J. Phys. Oceanogr., 19(10), 1588-1603.

Poulain, P.-M., A. Warn-Varnas, and P. P. Niiler (1996), Near-surface circulation of the Nordic Seas as measured by Lagrangian drifters, J. Geophys. Res., 101(C8), 18,237-18,258.

Rossby, T., M. D. Prater, and H. Søiland (2009), Pathways of inflow and dispersion of warm waters in the Nordic Seas, J. Geophys. Res., 114, C04011, doi:10.1029/2008JC005073.

Søiland, H., M. D. Prater, and T. Rossby (2008), Rigid topographic control of currents in the Nordic Seas, Geophys. Res. Lett., 35, L18607, doi:10.1029/2008GL034846. 
Spall, M. A. (2004), Boundary currents and watermass transformation in marginal seas, J. Phys. Oceanogr., 34(5), 1197-1213.

Speer, K. G., J. Gould, and J. H. LaCasce (1999), Year-long float trajectories in the Labrador Sea Water of the eastern North Atlantic Ocean, Deep Sea Res. Part II, 46(1), 165-180.

Stammer, D. (1997), Global characteristics of ocean variability estimated from regional TOPEX/POSEIDON altimeter measurements, J. Phys. Oceanogr. 27(8), 1743-1769.

Swenson, M. S., and P. P. Niiler (1996), Statistical analysis of the surface circulation of the California Current, J. Geophys. Res., 101(C10), $22,631-22,645$
Taylor, G. I. (1921), Diffusion by continuous movements, Proc. London Math. Soc., 20(2), 196-211.

M. Andersson and K. A. Orvik, Geophysical Institute, University of Bergen, PO Box 7803, N-5020 Bergen, Norway. (maria.andersson@gfi. uib.no)

I. Koszalka and J. H. LaCasce, Institute of Geosciences, University of Oslo, PO Box 1022 Blindern, N-0315 Oslo, Norway.

C. Mauritzen, Norwegian Meteorological Institute, PO Box 43 Blindern, N-0313 Oslo, Norway. 